\title{
Progesterone in Assisted Reproduction: Classification, Pharmacology and Its Clinical Coorelation: A Commentary
}

\author{
Rathod $\mathrm{K}^{1 *}$, Purohit $\mathrm{P}^{2}$, Kunde $\mathrm{K}^{3}$ and \\ Narvekar $\mathbf{N}^{4}$ \\ ${ }^{1}$ Consultant in Obstetrics and Gynaecology Whipps \\ Cross Hospital, London UK \\ ${ }^{2}$ Consultant in Obstetrics and Gynaecology Princess \\ Royal University Hospital, London UK \\ ${ }^{3}$ Consultant Obstetrics and Gynaecologist, Guys and \\ St Thomas' Hospital, London UK \\ ${ }^{4}$ Consultant and Sub-specialist in Assisted \\ Reproduction Kings College Hospital, London UK
}

This article was published in the following Scient Open Access Journal: Women's Health \& Gynecology

Received January 22, 2020; Accepted January 31, 2020; Published February 06, 2020

\begin{abstract}
The modulating effects of progesterone on endometrium structure and function are the basis for successful outcome in reproductive treatments. Considering this, progesterone has a big role in treatment of infertility and supporting the ongoing pregnancy. In this review article we have attempted to review different forms of progesterone, their metabolism in the body and the role played by exogenous as well as endogenous progesterone in assisted reproductive technologies (ART). Elevated serum progesterone levels at the end of the follicular phase in controlled ovarian stimulation (COS) leads to a poorer ongoing pregnancy rate in IVF cycles due to reduced endometrial receptivity.
\end{abstract}

Keywords: Progesterone, luteal phase support (LPS), in-vitro fertilization (IVF), Ovarian hyperstimulation (OHSS), Controlled ovarian stimulation (COS), Artificial reproductive technology (ART).

\section{Learning objectives}

- Progesterone

- Mechanism of action of Progesterone

- Classification of progesterone

- Pharmacokinetics and dynamics of progesterone

- Preparation of progesterone's

- Potential advantages of progesterone in assisted reproduction

- Cons of elevelated serum progesterone levels in ART

\section{Introduction}

It is a natural hormone ( $\mathrm{C}-21$ steroid) produced mainly by the theca lutein cells of the corpus luteum. It is also secreted by the adrenal cortex in a small amount and by placenta. Progesterone produces secretory endometrium in an oestrogen-primed endometrium. Natural progesterone's are rapidly metabolised and inactivated when administered by the oral route and as such, it is to be used parenterally. Recently, a number of compounds were synthesised having properties of progesterone and could be given in a tablet form. These are called progestational agents, gestanes, progestogens or progestins.Progesterone is secreted from the luteinised theca-granulosa cells of the corpus luteum. A trace is amount is however secreted from the theca-granulosa cells of the follicle and also from the ovarian stroma.

\section{Classification of progesterone}

\section{Pharmacokinetics and Pharmacodynamics}

(Table 1) The progesterone receptor (PR) has two major forms, designated as $\mathrm{A}$ and $\mathrm{B}$ receptors [2] which differ in their molecular weight. The two forms are expressed by a single gene, the two forms are a consequence of transcription from distinctly different promoters in a complex system of transcription regulations [3]. The effects of progesterone are mediated by progesterone receptors (PR) which exert their effects mainly by regulating the expression of specific target genes. The expression of PR is oestrogen-dependent in its target tissues. Therefore, the action
${ }^{*}$ Corresponding Author: Kunal Rathod, Consultant in Obstetrics and Gynaecology Whipps Cross Hospital London UK. 


\begin{tabular}{|c|c|}
\hline \multicolumn{2}{|c|}{ Table 1} \\
\hline Progesterone derivative & Progesterone content \\
\hline I. Progesterone & Natural progesterone* \\
\hline II. Retroprogesterone & Dydrogesterone* $^{*}$ \\
\hline III.Progesterone derivative & Medrogestone \\
\hline $\begin{array}{l}\text { IV. Pregnane progestogen ( } 17 \mathrm{OH} \\
\text { Progesterone derivaties) }\end{array}$ & $\begin{array}{l}\text { Medroxy progesterone acetate } \\
\text { Megestrol acetate } \\
\text { Cyproterone acetate* }^{*} \\
17 \text { alpha hydroxyl progesterone acetate } \\
\text { Chlormadinone acetate }^{*}\end{array}$ \\
\hline V. Norpregnane Progestogens & $\begin{array}{l}\text { Nomegesterol acetate } \\
\text { Gestonorone caproate }\end{array}$ \\
\hline VI. 19- Nor progesterone derivative & $\begin{array}{l}\text { Demegestone } e^{\star *} \\
\text { Promegestone }^{\star *} \\
\text { Nesterone }^{\star \star} \\
\text { Trimegestone }^{\star *}\end{array}$ \\
\hline $\begin{array}{l}\text { VII. Alkyl derivatives of } 19 \text { nor } \\
\text { testosterone } \\
\text { 1] Oestrane derivative } \\
\text { 2] Gonane derivative }\end{array}$ & 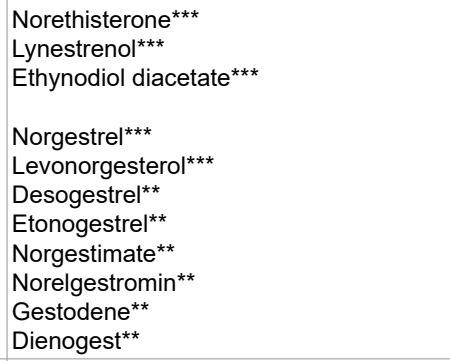 \\
\hline VIII. Spironolactone derivative & Drospirenone+ \\
\hline IX. Unsaturated 19 nonsteroidal & Gestrinone \\
\hline
\end{tabular}

*No androgenic effect

** Less Androgenic Action

***High Androgenic action

+ AntiMineralocortcoid action

of progesterone requires the priming treatment of oestrogen to induce PR.

The physiological levels of progesterone in women range from $0.23 \mathrm{ng} / \mathrm{ml}$ in the follicular phase to $8.3-25 \mathrm{ng} / \mathrm{ml}$ in the luteal phase and 21 to $200 \mathrm{ng} / \mathrm{ml}$ in pregnancy.

The secretion of progesterone during the luteal phase is episodic and changes closely with LH surges [4]. Progesterone is rapidly metabolised and requires frequent dosing regimen. 96.7 $\%$ of the progesterone is in a bound form and remaining is in an active from. It is metabolised in liver and excreted as sodium pregnanediol glucuronide in urine.

Progesterone can be administered orally, intravaginally, intrarectally or intramuscularly.

\section{Oral progesterone}

A systematic review and meta-analysis [5] of oral dydrogesterone and vaginal progesterone for luteal phase support showed that oral progesterone provided similar rates on live birth/on-going pregnancy and clinical pregnancy rates. Dydrogesterone is certainly a reasonable option and can be used based on the cost and side effects.

Oral preparations that are available and can be used for luteal phase support (LPS) are dydrogesterone $10 \mathrm{mg}$, three times a day, in a micronised form as $400 \mathrm{mg}$ twice or thrice a day, or as medroxyprogesterone acetate 10 or $40 \mathrm{mg}$ once a day.

Uterogestone is naturally available micronised progesterone and is used orally and vaginally for LPS. Its dose for LPS is $200 \mathrm{mg}$ three times a day. It is used from the day of embryo transfer until at least 7 to 12 weeks of pregnancy.

A major cause of cycle cancellation during controlled ovarian hyperstimulation $(\mathrm{COH})$ in women undergoing in vitro fertilisation (IVF) is the occurrence of premature luteinising hormone (LH) surges. A retrospective study [6] involving 374 patients were given human menopausal gonadotrophin (HMG) and uterogestan from day 3 of the cycle until the day of trigger showed that there is no significant difference in the mature oocyte rate, cleavage rate, clinical pregnancy rate or implantation rate. The study shows that Utrogestan is an effective oral alternative for preventing premature LH surges in women undergoing $\mathrm{COH}$, which will help to establish a convenient user regimen in combination with frozen embryo transfer (FET).

In a Lotus II randomised, open centre, a multicentre trial [7] comparing $30 \mathrm{mg}$ oral dydrogesterone with $8 \%$ micronised vaginal progesterone $90 \mathrm{mg} /$ day for LPS confirmed that dydrogesterone may replace MVP as the standard of care for luteal phase support in fresh-cycle IVF owing to its patientfriendly oral administration route.

\section{Intramuscular progesterone}

A prospective randomised study [8] on one hundred and eighty six patients comparing progesterone in oil $(100 \mathrm{mg}$, IM daily), intravaginal progesterone $400 \mathrm{mg}$, twice daily) and 17 -ahydroxyprogesterone caproate $(375 \mathrm{mg}$, every three days) showed no statistical difference for biochemical, clinical and ongoing pregnancy rates.

IM progesterone is absorbed rapidly, reaching its high plasma concentrations within two hours and peak concentration within eight hours. It maintains a steady plasma concentration for up to 72 hours.

The disadvantages of the IM route include local pain and discomfort at the injection site, the risk for adverse inflammatory reactions and abscesses at the injection sites and the rare complications of a severe allergic reaction, acute respiratory distress syndrome, and eosinophilic pneumonitis, which can form three weeks after the first injection [9]. IM injection is also uncomfortable for the patient and can produce serious side effects, such as injury to the sciatic nerve with impairment of the sensory or motor function of the lower extremity [10] as well as a reaction to the oil vehicle. I.M.

Progesterone doses that can be given are, in an oil base form at doses of $12.5,25,50$ or $100 \mathrm{mg}$ daily, or as 17 alpha-hydroxy progesterone $375 \mathrm{mg}$ every third day.

Lubion is an injectable preparation of synthetic progesterone. It is a water-soluble preparation. It is given as $25 \mathrm{mg}$ subcutaneous or intramuscular injections once a day from the day of oocyte retrieval until 12 weeks of pregnancy. This dose is equivalent to the physiologic amount of progesterone produced daily by the ovary in mid-luteal phase.

\section{Vaginal or rectal progesterone}

Vaginal administration of progesterone offers a number of advantages in terms of patient convenience and tolerability. It is a most patient friendly option, patients have the least discomfort and the greatest ease of administration with this route. 
Table 2

\begin{tabular}{|l|l|l|}
\hline \multicolumn{1}{|c|}{ Preparation } & \multicolumn{1}{c|}{ Indication } & Dose \\
\hline Crinone vaginal gel 8\% & Inadequate luteal phase, ART & 1 applicatorful daily \\
\hline Cyclogest, Vaginal or rectal & Inadequate luteal phase, ART & $200-800 \mathrm{mg}$ in divided dose. \\
\hline Lutigest & Luteal phase support in ART & $100 \mathrm{mg} \mathrm{3} \mathrm{times/day}$ \\
\hline Utrogestan & Luteal phase support in ART & 1 capsule 200mg, 3 times/day \\
\hline
\end{tabular}

A prospective study [11] to assess tolerability, convenience, and ease of administration of vaginal progesterone and injectable progesterone in oil given for luteal phase support was completed by infertile women diagnosed with PCOS and planning to undergo IVF found it very or somewhat convenient to insert vaginal progesterone even if it is two to three times per day.

In long agonist, IVF/ICSI-ET cycles, positive $\beta$-hCG, clinical pregnancy, and ongoing pregnancy rates do not significantly differ between normoresponder patients receiving micronised progesterone vaginal capsule $(600 \mathrm{mg} /$ day) and those receiving progesterone vaginal gel $(180 \mathrm{mg} /$ day) for LPS [12].

A 'first uterine pass effect' occurs when drugs are delivered vaginally, thereby providing an explanation for the unexpectedly high uterine concentrations relative to the low serum concentration observed after vaginal administration. The vaginal route permits targeted drug delivery to the uterus, maximising the desired effects while minimising the potential for adverse systemic effects [13].

Endometrial progesterone concentration reaches a steady-state within five hrs after vaginal administration [14]. Progesterone levels remain elevated for about 48 hrs with prolonged bioavailability. In a systematic review [15] of 18 RCT's comparing vaginal preparations for LPS; crinone, cyclogest, lutigest and uterogestan vaginal preparations were equally effective and safe for assisted reproductive technology cycles.

Vaginal preparations available in the UK: Progesterone for luteal phase is started from the day of ovulation or oocyte retrieval until 30 days after the positive pregnancy test (table 2).

\section{Luteal phase deficiency and support}

The luteal phase is defined as the period between ovulation and either the establishment of a pregnancy or the onset of menses usually two weeks later. Following ovulation, the luteal phase of a natural cycle is characterised by the formation of a corpus luteum, which secretes steroid hormones, including progesterone (P) and estradiol (E2). If conception and implantation occur, the developing blastocyst secretes human chorionic gonadotrophin (HCG). The role of HCG produced by the embryo is to maintain the corpus luteum and its secretions.

Luteal phase defect (LPD), or luteal insufficiency, occurs when the luteal phase is shorter than normal, progesterone levels during the luteal phase are below normal, or both.

Diagnostic tests for luteal phase deficiency are influenced by and based on the following physiologic observations:

1. Normal luteal phase length is relatively fixed at 12-14 days.

2. Progesterone levels peak in non-pregnancy cycles 6-8 days after the ovulation.

3. Progesterone is secreted in pulses.
4. The endometrial response is a reflection of the follicular phase oestrogen and the luteal-phase oestrogen and progesterone.

5. Once implantation occurs, progesterone secretion by the corpus luteum depends on rising human chorionic gonadotropin (HCG) levels.

6. Failure of HCG levels to increase directly causes corpus luteum failure and a decline in progesterone levels [17]

In the context of assisted reproduction techniques, luteal phase support (LPS) is the term used to describe the administration of medication aimed at supporting the implantation process. It is used in the fresh and frozen embryo transfer cycle in a similar way. In an attempt to enhance the probability of a pregnancy, different doses, durations and types of treatments for LPS have been evaluated. It is commenced on the day of oocyte retrieval and can be given for lengths of time that varied from four weeks until 10 to 12 weeks of a pregnancy.

Stimulated IVF cycles are associated with luteal phase defect and different doses, types and duration of LPS has been recommended. There is still no agreement regarding the optimal supplementation scheme. Both hCG and progesterone have similar effects on LPS although hCG is associated with increased risk of ovarian hyperstimulation syndrome. The supraphysiological levels of steroids during $\mathrm{COH}$ inducing negative feedback on the pituitary gland has been implicated for poor luteal phase support [18].

Although widely used, IM progesterone is uncomfortable and inconvenient for patients. By contrast, the vaginal progesterone gel is more convenient and easier to use. Mostly commonly used regimen is progesterone $400 \mathrm{mg}$ pessary twice a day or $8 \%$ gel once a day until the day of a pregnancy test.

\section{Stimulated intrauterine insemination (IUI) cycles}

Progesterone is given one day after the HCG trigger injection or after urine LH surge. It is given most commonly as a pessary, $400 \mathrm{mg}$ twice a day until two weeks or until periods whichever is earlier. In case of a missed period and a positive pregnancy, it can be stopped or continued till 12 weeks of pregnancy.

A prospective randomised controlled trial [19] of controlled ovarian stimulation with IUI in which one hundred and fourty eight women received treatment (vaginal progesterone) from the day of IUI and one hundred and fourty two women received no treatment from the day of IUI showed clinically significant pregnancy rates in the treatment group.

In a meta-analysis of five randomised controlled trials [20] comparing luteal phase support in a clomiphene citrate cycle versus gonadotrophin cycle and clinical pregnancy rate (CPR) as their primary outcome showed significantly increased CPR.

\section{Human Chorionic Gonadotrophin as luteal phase support}

GnRHa triggers to induce ovulation showed that exogenous 
progesterone administration without hCG supplementation is insufficient to obtain satisfactory pregnancy rates and that daily micro-dose hCG administration provides good LPS [21]. The luteal phase administration of human chorionic gonadotrophin (hCG) was associated with a higher incidence of severe OHSS than supplementation with progesterone alone [22]. It is likely that the longer duration of time and the greater affinity with which HCG binds to the LH receptors are responsible for the increased luteotrophic stimulation that results in the development of OHSS, particularly in susceptible women.

\section{Gonadotrophin releasing hormone as luteal phase support}

In a prospective trial [23] with serum oestradiol levels of over $2500 \mathrm{pg} / \mathrm{ml}$ after use of a GnRH agonist for triggering ovulation were randomised to $\mathrm{GnRH}$ agonist luteal support $(0.1 \mathrm{mg})$ subcutaneously every other day) or to a control group supported by $(80 \mu \mathrm{g})$ of recombinant human chorionic gonadotrophin (HCG) GnRH as safe and effective luteal phase support. The luteal phase support was started on day three after the embryo transfer.

\section{Serum progesterone and ART Success}

The role of progesterone elevation during the luteal phase and its impact on in-vitro fertilisation (IVF) outcome has been debatable for many years.

Patients treated with GnRH antagonists and gonadotrophins, progesterone elevation on the day of HCG administration is significantly associated with a lower probability of clinical pregnancy. Serum progesterone levels of $>1.5 \mathrm{ng} / \mathrm{ml}$ are associated with lower ongoing pregnancy rates following IVF/ ICSI cycles irrespective of the GnRH analogue used for pituitary down-regulation [24]. Elevated serum progesterone levels at the end of the follicular phase in controlled ovarian stimulation (COS) leads to a poorer ongoing pregnancy rate in the IVF cycles due to reduced endometrial receptivity.

High progesterone levels on the day of trigger alter with endometrial receptivity and implantation [25]. In a large retrospective study [26] involving 11,055 women who had IVFET and FET cycles there was an inverse correlation between implantation rate and levels of progesterone on the day of the trigger with levels of $1.5 \mathrm{ng} / \mathrm{l}, 1.75 \mathrm{ng} / \mathrm{l}$ and $2.25 \mathrm{ng} / \mathrm{l}$.

It has been suggested that a level of premature progesterone rise during the follicular phase and elevated progesterone levels $(>2.0 \mathrm{ng} / \mathrm{ml})$ before oocyte maturation were consistently detrimental to the oocyte quality [27].

In a retrospective analysis [28] of 1702 IVF/ICSI cycle Baseline (day two of the menstrual cycle) serum progesterone concentration and history of progesterone elevation (PE) are baseline variables that can predict the occurrence of $\mathrm{PE}$ on the day of HCG independently of the intensity of ovarian stimulation and for similar occurrence in subsequent cycles.

\section{Conclusion}

Progesterone has a big role to play in our clinical practice. Oral and Vaginal progesterone has equal benefits and is better tolerated by our patients than intramuscular preparation for luteal phase support from 7-12 weeks after confirmation of pregnancy

\section{Conflict of interest}

None to declare.

\section{References}

1. Dutta DC, Konar H. DC Dutta textbook of Gynaecology including contraception, $6^{\text {th }}$ rev. ed. Kolkata: New central book agency $(P)$ Ltd; c2013. Chapter 31, Hormones in Gynaecological practise; p 531

2. Reiner GC, Katzenellenbogen BS. Characterization of estrogen and progesterone receptors and the dissociated regulation of growth and progesterone receptor stimulation by estrogen in MDA-MB-134 human breast cancer cells. Cancer Res. 1986;46(3):1124-1131.

3. Kastner P, Krust A, Turcotte B, et al: Two distinct estrogen-regulated promoters generate transcripts encoding the two functionally different human progesterone receptor forms A and B. EMBO J. 1990;9(5):1603-1614.

4. Filicori M, Santoro N, Merriam GR, Crowley WF Jr. Characterization of the physiological pattern of episodic gonadotropin secretion throughout the human menstrual cycle. J Clin Endocrinol Metab. 1986;62(6):1136-1144.

5. Barbosa MWP, Valadares NPB, Barbosa ACP, Amaral AS, Iglesias JR Nastri CO, Martins WP, Nakagawa HM. Oral dydrogesterone vs. vaginal progesterone capsules for luteal-phase support in women undergoing embryo transfer: a systematic review and meta-analysis. JBRA Assist Reprod. 2018;1;22(2):148-156.

6. Zhu $\mathrm{X}$, Zhang $\mathrm{X}, \mathrm{Fu}$ Y. Utrogestan as an effective oral alternative for preventing premature luteinizing hormone surges in women undergoing controlled ovarian hyperstimulation for in vitro fertilization. Medicine (Baltimore). 2015;94(21):e909.

7. Griesinger G, Blockeel C, Sukhikh GT, et al. Oral dydrogesterone versus intravaginal micronized progesterone gel for luteal phase support in IVF: a randomized clinical trial. Hum Reprod. 2018;1;33(12):2212-2221.

8. Moini A, Zafarani F, Eslami B, Sadeghi M, Kamyabi Z, Jahangir N. Comparing intramuscular progesterone, vaginal progesterone and 17 -hydroxyprogestrone caproate in IVF and ICSI cycle. Iran J Reprod Med. 2011;9(2):119-124.

9. Bouckaert Y, Robert F, Englert Y, De Backer D, De Vuyst P, Delbaere A. Acute eosinophilic pneumonia associated with intramuscular administration of progesterone as luteal phase support after IVF: case report. Hum Reprod. 2004;19(8):1806-1810.

10. Park CW, Cho WC, Son BC. latrogenic Injury to the Sciatic Nerve due to Intramuscular Injection: A Case Report. Korean $J$ Neurotrauma. 2019;8;15(1):61-66.

11. Beltsos AN, Sanchez MD, Doody KJ, Bush MR, Domar AD, Collins MG. Patients' administration preferences: progesterone vaginal insert (Endometrin $\AA$ ) compared to intramuscular progesterone for Luteal phase support. Reprod Health. $2014 ; 11 ; 11: 78$.

12. Gün İ, Özdamar Ö, Şahin S, Çetingöz E, Sofuoğlu K. Progesterone vaginal capsule versus vaginal gel for luteal support in normoresponder women undergoing long agonist IVF/ICSI cycles. Ginekol Pol. 2016;87(5):372-377.

13. Bulletti C, de Ziegler D, Flamigni C, Giacomucci E, Polli V, Bolelli G, Franceschetti $F$. Targeted drug delivery in gynaecology: the first uterine pass effect. Hum Reprod. 1997;12(5):1073-1079.

14. Cicinelli E, de Ziegler D, Bulletti C, Matteo MG, Schonauer LM, Galantino P. Direct transport of progesterone from vagina to uterus. Obstet Gynecol. 2000;95(3):403-406.

15. Child T, Leonard SA, Evans JS, Lass A. Systematic review of the clinical efficacy of vaginal progesterone for luteal phase support in assisted reproductive technology cycles. Reprod Biomed Online. 2018;36(6):630645.

16. Joint Formulatory Committee. British National Formulatory (online) London: BMJ Group and Pharmaceutical Press.

17. Strott CA, Cargille CM, Ross GT, Lipsett MB. The short luteal phase. J Clin Endocrinol Metab. 1970;30(2):246-251.

18. Fatemi HM, Popovic-Todorovic B, Papanikolaou E, Donoso P, Devroey P. An update of luteal phase support in stimulated IVF cycles. Hum Reprod Update. 2007;13(6):581-590. 
Citation: Rathod K, Purohit P, Kunde K Narvekar N (2020). Progesterone in Assisted Reproduction: Classification, Pharmacology and its clinical coorelation: A Commentary

19. Aali BS, Ebrahimipour S, Medhdizadeh S. The effectiveness of luteal phase support with cyclogest in ovarian stimulated intra uterine insemination cycles: A randomized controlled trial. Iran J Reprod Med. 2013;11(4):309-314.

20. Miralpeix E, González-Comadran M, Solà I, Manau D, Carreras R, Checa MA. Efficacy of luteal phase support with vaginal progesterone in intrauterine insemination: a systematic review and meta-analysis. J Assist Reprod Genet. 2014;31(1):89-100.

21. Andersen CY, Fischer R, Giorgione V, Kelsey TW. Micro-dose hCG as luteal phase support without exogenous progesterone administration: mathematical modelling of the hCG concentration in circulation and initial clinical experience. J Assist Reprod Genet. 2016;33(10):1311-1318.

22. McClure N, Leya J, Radwanska E, Rawlins R, Haning RV Jr. Luteal phase support and severe ovarian hyperstimulation syndrome. Hum Reprod. 1992;7(6):758-764.

23. Wiser A, Klement $A H$, Shavit $T$, et al. Repeated $\mathrm{GnRH}$ agonist doses for luteal support: a proof of concept. Reprod Biomed Online. 2019;39(5):770 776.
24. Bosch E, Labarta E, Crespo J, et al. Circulating progesterone levels and ongoing pregnancy rates in controlled ovarian stimulation cycles for in vitro fertilization: analysis of over 4000 cycles. Hum Reprod. 2010;25(8):20922192.

25. Fanchin R, de Ziegler D, Castracane V, Taieb J, Olivennes F, Frydman R. Physiopathology of premature progesterone elevation*. Fertility and Sterility. 1995; 64(4):796-801.

26. Xu B, Li Z, Zhang H, et al. Serum progesterone level effects on the outcome of in vitro fertilization in patients with different ovarian response: an analysis of more than 10,000 cycles. Fertil Steril. 2012;97(6):1321-1327.e1-4.

27. Huang B, Ren X, Wu L, et al. Elevated Progesterone Levels on the Day of Oocyte Maturation May Affect Top Quality Embryo IVF Cycles. PLoS One. 2016;8;11(1):e0145895

28. Venetis CA, Kolibianakis EM, Bosdou JK, et al. Basal serum progesterone and history of elevated progesterone on the day of hCG administration are significant predictors of late follicular progesterone elevation in $\mathrm{GnRH}$ antagonist IVF cycles. Hum Reprod. 2016;31(8):1859-1865.

Copyright: (c) 2020 Kunal Rathod et al. This is an open-access article distributed under the terms of the Creative Commons Attribution License, which permits unrestricted use, distribution, and reproduction in any medium, provided the original author and source are credited. 